\title{
Small step forward in global food labelling
}

G lobal standards for "mandatory nutrition labelling" on the back of food packaging appear to be in the offing but standards for the front of packages appear to be a distant dream.

The guidelines will be crafted this summer by the Codex Food Labelling Committee, which is part of the Codex Alimentarius Commission, created in 1963 by United Nations Food and Agricultural Organization and the World Health Organization to develop food standards, guidelines and codes of practice to protect consumer health and ensure fair trade practices with regard to food.

Proponents hope the back-of-package labels - which would articulate general information about such things as fat, protein, fibre and calorie content - will serve as an impetus to all nations to adopt official labelling requirements, if only because they would soon become a requisite element of international trade.

International standards should "empower" countries to adopt back-ofpackage labelling standards, says Bill Jeffery, national coordinator for the Canadian office of the Centre for Science in the Public Interest. "Calling it a mandatory standard is really like saying to national governments: 'You're permitted to have a mandatory standard without running afoul of international trade law'."

Proponents also believe that improved nutrition labelling would help to redress the growing incidence of noncommunicable diseases such as heart disease, stroke, diabetes and cancer, which are now responsible for up to two-thirds of all deaths globally, and are increasingly a burden in undeveloped nations as a consequence of population aging and the spread of risk factors associated with globalization and urbanization, according to a recent World Health Organization report, World Health Statistics 2011 (www.who.int/whosis/whostat/EN_WHS 2011_Full.pdf).

International standards should dissuade countries from reaching for the

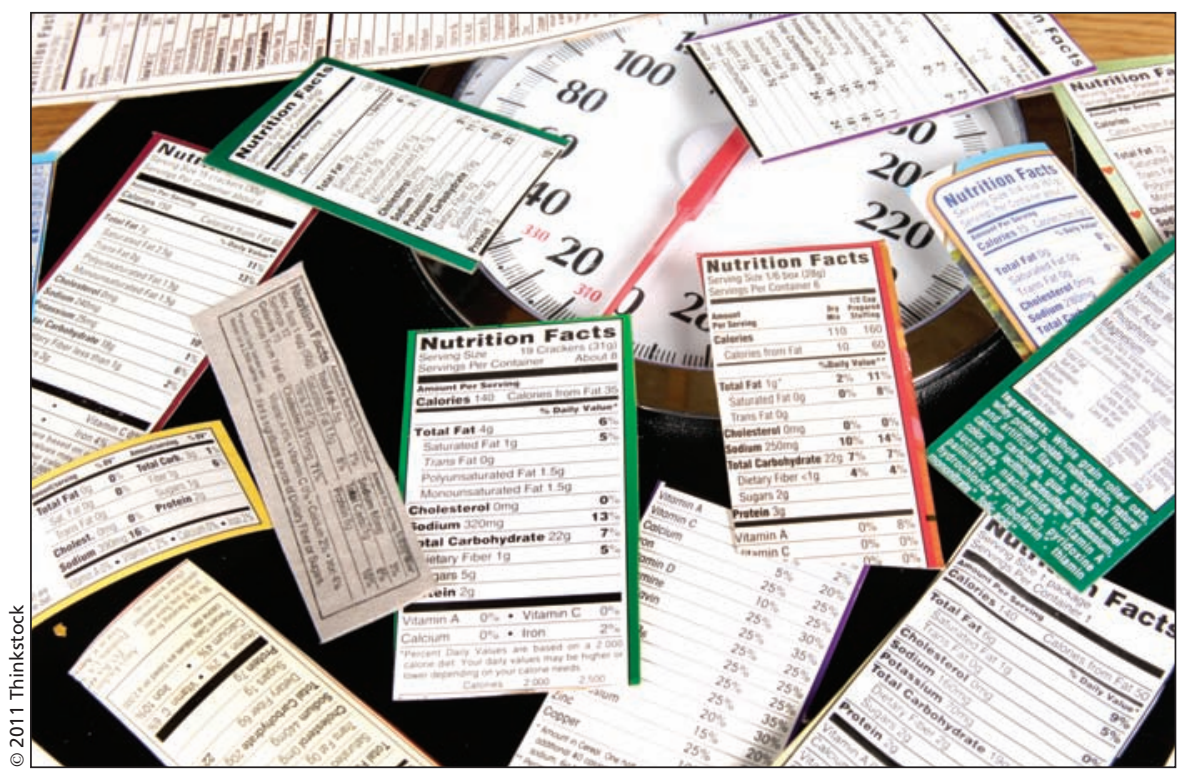

International guidelines for back-of-package nutrition labelling of foods will be developed by the Codex Alimentarius Commission over the course of the summer.

minimum when they introduce labelling requirements, Jeffery argues, adding that countries often use Codex Alimentarius Commission guidelines as the basis for their regulations.

That's in part because they would have to defend their laws to the World Trade Organization if they were ever challenged by another government, which could result in having to pay compensation to the complainant country, he says.

Canada is one of only a handful of countries that already has mandatory back-of-package labelling standards. Regulations adopted in 2002 "require that calories and the content of 13 core nutrients, including sodium, be listed on the labels of most pre-packaged foods," Health Canada spokesperson Gary Holub writes in an email.

While encouraged by the move to develop back-of-package labelling standards, Jeffery is disappointed that the Codex Alimentarius Commission hasn't taken a leadership role on front-of-package labelling. "Internationally there is such a problem with diet-related cancer, heart disease, stroke and diabetes and so forth that it really calls for innovative policies, and food policy leadership, not kind of waiting around until everyone jumps on one bandwagon."

Jeffery says standardized front-ofpackage labelling, particularly with regard to sodium, transfat, caloric and other nutrient content would have an enormous impact on public health.

Although several countries are experimenting with forms of front-ofpackaging labelling, such as the United Kingdom, which introduced a voluntary colour-coded traffic light system in 2007, (www.cmaj.ca/lookup/doi /10.1503/cmaj.081755), no nation has mandatory regulations.

Countries have typically left that to the discretion of their national governments rather than seeking global standards, says Selma Doyran, food standards officer with the secretariat of the Codex Alimentarius Commission. "Countries considered that it was not necessary at this stage to discuss the use of symbols and some countries considered that it would create more confusion and the priority is really to have clear description in the label on nutrient content" on back-of-package labels. 
That includes Canada. Health Canada spokesperson Olivia Caron writes that "Canada supported the decision to discontinue work on standardized symbols for ingredients identified in the WHO [World Health Organization] Global Strategy on Diet, Physical Activity and Health until such time as there may be information available to guide such work."

Jeffery argues that delay is a disservice to public health. "I think it's widely recognized that the health, economic and development burden of nutritionrelated illness is so enormous and seemingly so preventable that we have to take kind of aggressive action soon and not wait for a couple of decades until more evidence is in or national governments change their tactics."

The United States Institute of Medicine is currently conducting a study on a number of possible systems for front-ofpackage nutrition labelling. A report from phase one of the study, released in
October 2010, states that "regardless of system type, it would be useful to declare calorie and serving size information prominently in front-of-package symbols (http://books.nap.edu/openbook .php?record_id=12957). It also notes that the "most useful primary purpose of front-of-package rating systems and symbols would be to help consumers identify and select foods based on the nutrients most strongly linked to public health concerns for Americans."

Jeffery equates front-of-package labelling for foods to current requirements for tobacco and notes that it took decades to achieve tougher labelling for cigarettes despite evidence indicating that smoking caused cancer, heart disease and stroke.

"When the World Health Organization enacted the framework convention on tobacco-control that was taking more of a leadership role. It seemed clear that that was really a mechanism to drive change at the national level," he says. "I think that governments have to start thinking about a similar mechanism for nutrition-related policy reforms."

But back-of-package labelling is a small step forward, Jeffery adds. "We have to put a lot of stock, I think, in this upcoming United Nations high-level summit, hoping that government leaders are beginning to recognize that there are some enormous, economy-wide implications of having high-rates of preventable chronic diseases and that it's in everyone's interest to have policies that help curb those."

The labelling committee agreed to develop global standards for mandatory nutrition labelling during a gathering in Québec City, Quebec, May 9-13. The standards will be developed by an electronic working group headed by Australia and open to all interested countries. — Erin Walkinshaw, Ottawa, Ont.

CMAJ 2011. DOI:10.1503/cmaj.109-3909 